\title{
Depression and SSRI use in pregnancy associated with traits of autism in children
}

In this Research News story (BMJ 2014;349:g4835, doi:10.1136/ bmj.g4835), we incorrectly described Liz McDonald and Ian Jones as being chair and vice chair, respectively, of perinatal psychiatry at the Royal College of Physicians. In fact, they hold those positions at the Royal College of Psychiatrists.
Cite this as: BMJ 2014;349:94989

๑ BMJ Publishing Group Ltd 2014 